\title{
Historia de la universalización del acceso al agua y alcantarillado en Santiago de Chile (1970-1995)*
}

\author{
GÉRALDINE PFLIEGER** \\ ** Instituto de Estudios Políticos e Internacionales, Universidad de Lausanne, Suiza.
}

\begin{abstract}
What factors explain the growth of universal access to potable water and sewage networks in Santiago, Chile? We will analyse the respective roles of housing policies and the first wave of service reforms in achieving universal access to drinking water during the 1980s. The second part of the article focuses on the difficulties linked to urban growth in Gran Santiago that coincided with the expansion of water and sewer lines during the 1980s, eventually leading to a second wave of reforms. Finally, we shall examine the designo f the 1989 regulatory and management reforms and their effects on service access as it varies by social group and geographic location.
\end{abstract}

Keywords: water, sanitation, Santiago de Chile, access.

RESUMEN ¿Cuáles son los factores que explican la universalización de las redes de agua y de saneamiento en Santiago de Chile? Analizaremos los papeles respectivos de las políticas de la vivienda y de las primeras reformas del servicio en la universalización del acceso al agua potable a lo largo de los ochenta. En una segunda fase, destacaremos las dificultades que trae para estas redes el crecimiento urbano del Gran Santiago en los ochenta, las que generan una segunda ola de reformas. Estudiaremos, finalmente, el diseño de la reforma reglamentaria y gerencial de 1989 y sus efectos en términos de accesibilidad espacial y social al servicio.

Palabras claves: agua potable, alcantarillado, Santiago de Chile, acceso

* $\quad$ Recibido el 25 de julio de 2007, aprobado el 12 de diciembre de 2007.

Correspondencia: Prof. Géraldine Pflieger, Institut d'études politiques et internationales, Swiss Public Administration Netowork, Université de Lausanne, Bâtiment Vidy, CH 1015 Lausanne, Switzerland. Tel: +41.21.692.36.38. Fax: +41.21.692.31.45. E-mail: geraldine.pflieger@unil.ch. 


\section{Introducción}

Mientras que los servicios urbanos de las ciudades europeas o norteamericanas se han universalizado desde finales de los años '30 (Tarr y Dupuy, 1988), las ciudades de los países en desarrollo se enfrentan a un subequipamiento en redes domiciliarias en relación a los estándares de los países del norte. Por una parte, las ciudades de los países desarrollados habrían conocido, a lo largo de la segunda mitad del siglo XX, un ideal moderno de integración territorial a través de las redes, promovido por servicios integrados, monopolísticos y de propiedad pública (Graham y Marvin, 2001) ${ }^{1}$. Por otra parte, ese ideal moderno de infraestructura no habría sido alcanzado en los países en desarrollo, que han tenido que enfrentarse a deficiencias en los modos de gestión, a problemas de financiamiento y a dificultades en el control y planificación del crecimiento urbano (Coutard, 2002; Graham, 2002).

En este contexto, que revela el contraste entre el ideal moderno de los países del norte y los problemas de accesibilidad a los servicios esenciales por parte de los países de sur, Chile constituye un caso de excepción, caracterizándose simultáneamente por fuertes desigualdades sociales y espaciales, y por un acceso generalizado a servicios esenciales ${ }^{2}$. El proceso de universalización del acceso a los servicios urbanos refleja, en Chile, el despliegue de un ideal de infraestructura moderno en una ciudad fuertemente segregada, bajo el efecto de políticas de la vivienda y dinámicas residenciales de largo plazo. Esa fase de universalización puede delimitarse temporalmente entre 1970, cuando se rompe el crecimiento de la inaccesibilidad a los servicios, y 1995, fecha en que se completa la cobertura de red de alcantarillado.

Luego, ¿a lo largo del periodo, cuáles han sido los factores de universalización de las redes de agua y saneamiento? ¿Cuál ha sido el papel de las políticas urbanas en ese proceso? ¿Cuál ha sido la relación entre los diferentes modos de gestión de los servicios y el incremento de las tasas de acceso? ¿Cuáles han sido las consecuencias de esa universalización en términos de segregación social y espacial?

Para tratar estos asuntos hemos estudiado las políticas urbanas - de vivienda y de planificacióny la evolución de los modos de gestión de los servicios entre 1970 y 1995 . Nos hemos basado en un análisis de fuentes secundarias publicadas por economistas, politólogos y urbanistas relativas al crecimiento urbano, a las políticas de la vivienda y al desarrollo urbano, así como a las mutaciones de la gestión del agua y del saneamiento. También fueron realizadas entrevistas complementarias a técnicos y responsables de la distribución del agua, de la regulación del sector y algunos representantes del gobierno. Finalmente, hemos recogido y cartografiado las tasas de acceso al agua y al saneamiento publicadas en los censos de 1970, 1982 y 1992.

\footnotetext{
$1 \quad$ En el argumento de Graham y Marvin (2001), un modelo contemporáneo de fragmentación sucedió al ideal moderno de infraestructura -llamado splintering urbanism-, relacionado con el unbundling de las redes urbanas, con la crisis financiera de las infraestructuras, con las reformas liberales y con el abandono del ideal de integración espacial en la planificación urbana.

2 Santiago de Chile no es el único ejemplo de ciudad de América Latina que dispone de un acceso casi universal al agua potable y al alcantarillado. Otros países presentan tasas elevadas de acceso de las poblaciones urbanas al agua potable: 90\% en Colombia, en Honduras y en Brasil, 93\% en Uruguay y en Méjico, 99\% en Costa Rica (fuente: Organización Panamericana de la Salud, 2001).
} 
En primer lugar, analizaremos los papeles respectivos de las políticas de la vivienda y de las primeras reformas del servicio en la universalización del acceso al agua potable a lo largo de los ochenta. En una segunda fase, destacaremos las dificultades que trae para estas redes el crecimiento urbano del Gran Santiago en los ochenta, las que generan una segunda ola de reformas. Estudiaremos, finalmente, el diseño de la reforma reglamentaria y gerencial de 1989 y sus efectos en términos de accesibilidad espacial y social al servicio.

Mapa 1. Ingresos medios en los municipios del Gran Santiago, 1991.

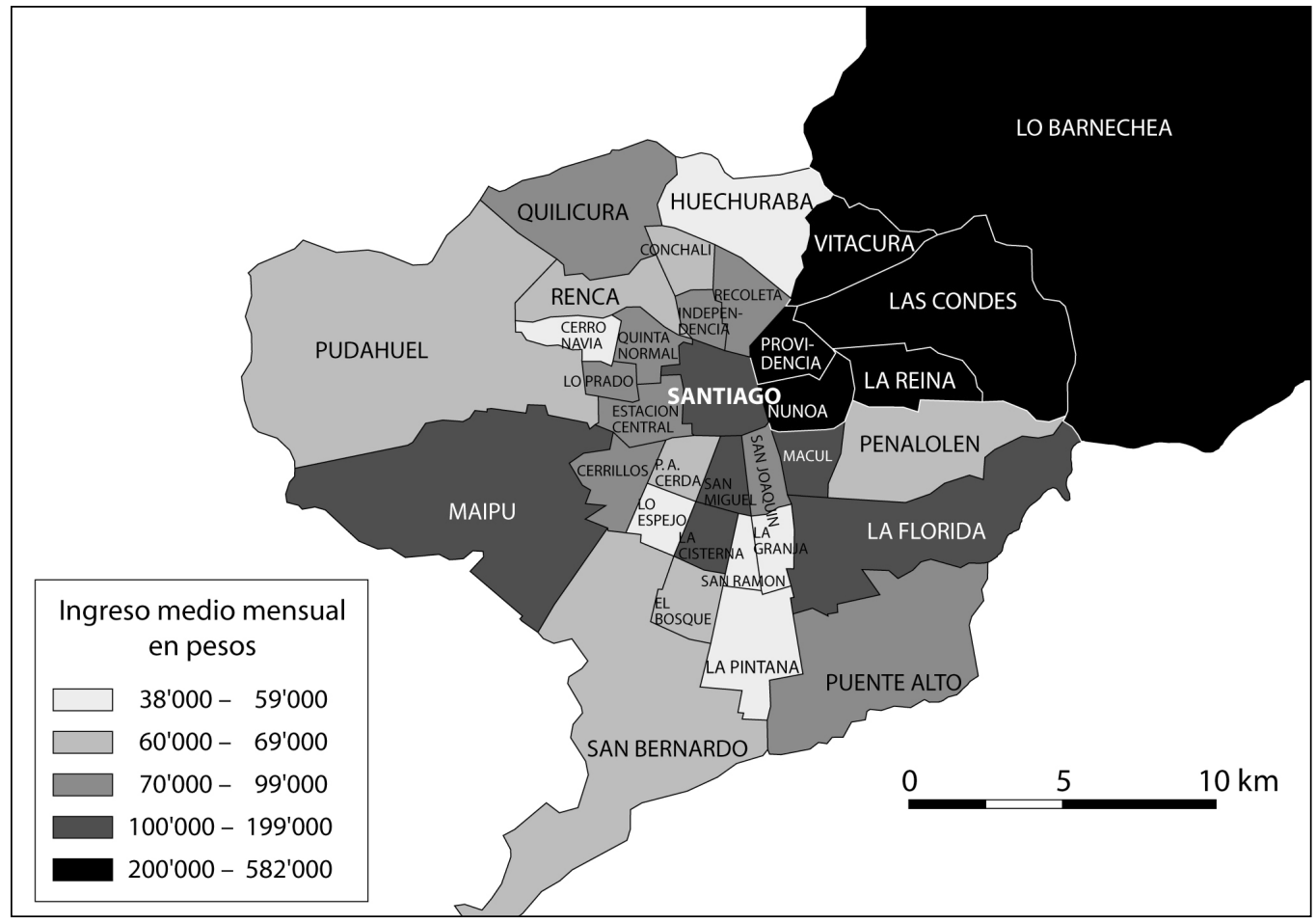

Fuente: Elaboración propia.

\section{5-1989: la política de la vivienda y las reformas gerenciales al servicio de la univer-} salización de las redes de agua potable

De acuerdo al censo de 1982, el acceso de las viviendas al agua potable y al alcantarillado ha mejorado considerablemente entre 1970 y 1982; la tasa de viviendas sin acceso al agua potable pasan del 16,9 al 2,5\%, la tasa de viviendas sin sistemas de eliminación de las aguas servidas (sin alcantarillado, ni fosa séptica) pasan del 25,5 al 14,5\%; entendiendo que en el mismo periodo el número de viviendas ha subido un 41\%, pasando de 615.962 a 869.323 (INE, 1970 y 1982).

En este sentido, ¿qué factores impulsaron el aumento de la tasa de conexión a las redes de agua y saneamiento? La universalización de las redes de agua y de alcantarillado puede ser imputada, en primer lugar, a la política de vivienda y urbanismo que, a partir de 1971 y durante dos décadas, disminuye violentamente la producción de vivienda precaria. Esta política de 
vivienda va a ser sostenida por la reactivación de las inversiones y por una primera reforma profunda de la gestión de los servicios, emprendida en 1977.

\section{El apoyo a la política de la vivienda}

A lo largo de los setenta, los problemas de los habitantes de Santiago para acceder al agua, al saneamiento y a la electricidad son ante todo consecuencia de las dificultades de alojamiento de hogares pobres y del desarrollo de barrios informales. La llegada al poder del Gobierno militar en 1973 se traduce en dos consecuencias radicales: por un lado, la creación de nuevos campamentos se detiene totalmente, parando la producción de nuevas viviendas precarias; por otro lado, la política pública de vivienda social iniciada por Allende es suspendida y el ritmo de producción de viviendas destinadas a hogares pobres se reduce claramente, desde 1974 y, sobre todo, después de 1978. Entre 1976 y 1977, después de una primera reducción del ritmo de construcción de viviendas públicas, la culminación de los proyectos iniciados bajo el Gobierno de Allende conduce a la generación de 38.000 viviendas públicas, para luego observar un abandono casi total de este tipo de programas hacia finales de los ochenta. Ahora, más allá de su abandono, se debe considerar que esa política no tuvo mayor efecto sobre la tasa de conexión al agua y al saneamiento. A nivel nacional, entre 1970 y 1982, 150.000 viviendas sociales públicas fueron construidas (INE citado en Paquette, 1998). A lo largo de ese mismo periodo, a escala del Gran Santiago, el número de viviendas sin acceso al agua pasó de 96.000 a 21.000; sin embargo, en 1982 había 128.000 viviendas que no disponían de un sistema de

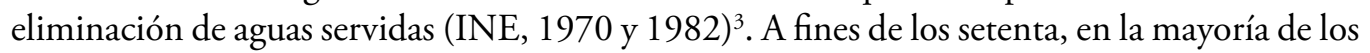
campamentos, donde vivían alrededor de 200.000 personas, fueron congelados durante más de cinco ańos el suministro formal de servicios de agua, de saneamiento o de electricidad.

No es hasta 1979, en el marco de la nueva Política Nacional de Desarrollo Urbano (PNDU) que los programas de acceso a la vivienda son reactivados. Esos programas de filosofía liberal renuncian a la política de vivienda pública; ahora el Estado desarrolla un papel central en el financiamiento de la vivienda, apoyando el acceso a la propiedad, pero no en su construcción.

En primer lugar, la destrucción de los barrios precarios permite incluir, por la vía de la violencia, a las áreas que hasta ese momento no disfrutaban de conexión a las redes domiciliaras. Entre 1979 y 1986, 246 campamentos han sido arrasados, y 150.000 personas desplazadas y realojadas. Si bien el objetivo indicado por el Gobierno era prevenir los riesgos de inundación para los campamentos asentados cerca de las áreas fluviales y de devolver a sus propietarios los terrenos ocupados de forma ilegal, el realojamiento de los habitantes de esos barrios permitió sobre todo a los municipios más acomodados deshacerse de sus campamentos. Los municipios que reciben a las familias realojadas se situaban casi todos en el suroeste de la ciudad, donde los terrenos eran más baratos (La Pintana, Renca, Puente Alto, La Granja, Cerro Navia y San Bernardo).

\footnotetext{
3 Para ser comparables con los datos de 1970, esas cifras tienen en cuenta las viviendas con agua potable, agua procedente de la red pública o de pozos o aun de reservorios. Hay que añadir así a las 21.000 viviendas no conectadas al agua, alrededor de 3.500 viviendas disponiendo del agua potable, pero no conectadas a la red pública (fuente: INE, 1982).
} 
En segundo lugar, el programa llamado de viviendas básicas propuso a las familias desplazadas viviendas de substitución según una tipología estandarizada y con acceso al agua, al alcantarillado y a la electricidad. Estas viviendas permitieron el acceso social a la propiedad. Los hogares se beneficiaban de una subvención del Estado que podía alcanzar hasta el 75\% del costo de la vivienda. A nivel nacional, entre 1979 y 1980, 200.733 viviendas de esa clase fueron construidas (MINVU, citado en Paquette, 1998, p. 199). Al igual que para la promoción inmobiliaria privada, la reglamentación urbana obligaba, desde inicios de los setenta, a los constructores a hacerse cargo de la conexión de cada nueva vivienda construida a las redes de distribución de agua, de electricidad y de alcantarillado. El costo de la conexión era, así, parcialmente integrado al costo de construcción de las viviendas, siendo los distribuidores los encargados de generar los recursos suficientes y de nivelar la red de distribución.

En tercer lugar, una parte de los campamentos se benefició de un programa de saneamiento, llamado "radicación", apoyado por el Banco Interamericano de Desarrollo (BID). En ese caso, un título de propiedad fue otorgado a las familias (Larraín, 1994, p. 109), así como la construcción de un cuarto de conexión con alcantarillado, agua potable y electricidad. Las familias podían aumentar el tamaño del cuarto a continuación, o construir nuevas viviendas en su entorno. Esas casetas sanitarias fueron todas construidas en los barrios informales asentados en los municipios pobres (Peñalolén, La Florida, La Cisterna, El Bosque o Pudahuel). Ningún municipio rico, tales como Providencia, Las Condes, Vitacura o Lo Barnechea, mantuvo un solo campamento en su interior, ya que todos fueron destruidos.

Con el programa de saneamiento de los barrios informales, entre 1979 y 1992, más de 48.800 accesos nuevos al agua, al saneamiento y a la electricidad fueron creados en el Gran Santiago. Entre 1989 y 1987 las intervenciones se concentraron en los campamentos (alrededor del $75 \%$ de los accesos creados), para después orientarse hacia los barrios de la Operación Sitio conducida en los sesenta y que no disponían aún de infraestructura pública (representando el $25 \%$ restante de los accesos creados) (Hidalgo, 2004, p. 232).

La política de acceso social a la propiedad y al saneamiento de barrios populares tuvo, sin embargo, una dimensión segregativa. La Política Nacional de Desarrollo Urbano de 1979 hizo de las periferias la única posibilidad de asentamiento de barrios de viviendas sociales. No obstante esta política urbana y social fue muy discriminatoria, las redes urbanas se desarrollaron de manera igualitaria a escala de ciudad a lo largo de los años ochenta. Si ańadimos los 48.800 puntos de acceso creados en las viviendas informales a los de las 28.800 nuevas viviendas de acceso social construidas por las familias desplazadas, más de 68.000 nuevas conexiones a redes domiciliarias proceden directamente de la política de vivienda social. La red de agua potable en particular se universalizó, a la vez que siguió el crecimiento rápido del número de viviendas. Con infraestructuras de base y satisfaciendo los estándares mínimos de desarrollo social y sanitario, las redes de agua y de saneamiento fueron concebidas como los únicos vínculos entre territorios fuertemente diferenciados socialmente y fragmentados a nivel institucional. Así, entre los años 1982 y 1992, se asiste a una extensión de la cobertura de la red de agua, en particular en sectores marginados, al sur y al noreste de la aglomeración. 
En 1982, en plena fase de reactivación de la política de la vivienda social, la cartografía de la distribución de los municipios por tasa de acceso al agua y al saneamiento ofrece la imagen de una geografía particularmente desigual en términos de tasa de cobertura. Esa distribución es un reflejo de las desigualdades de renta así como de la dicotomía entre urbanizaciones recientes y antiguas.

En lo que se refiere al acceso al agua potable, los municipios del centro y los municipios más acomodados del cuadrante noreste presentan todos tasas de conexión iguales o superiores a la media del 97\% (INE, 1982). Los únicos municipios que se distinguen en 1982 por tasas de acceso al agua potable más bajas son los municipios del cuadrante sureste y de la segunda corona (La Florida, Peñalolén, San Bernardo, Pudahuel, Quilicura), que presentan simultáneamente las tasas más altas de poblaciones viviendo en campamentos y las tasas más bajas de conexiones al agua potable (comprendidas entre el 86 y el 94\%). Estos municipios, todos abastecidos por el distribuidor público (Empresa Metropolitana de Obras Sanitarias, EMOS), se caracterizan por una urbanización reciente y rápida, y por un desarrollo polarizado de viviendas informales y precarias. Y en lo que se refiere al saneamiento, la geografía de la red aparece como más desigual aun.

Mapa 2. Tasas de acceso de las viviendas al agua en los municipios del Gran Santiago, 1982.

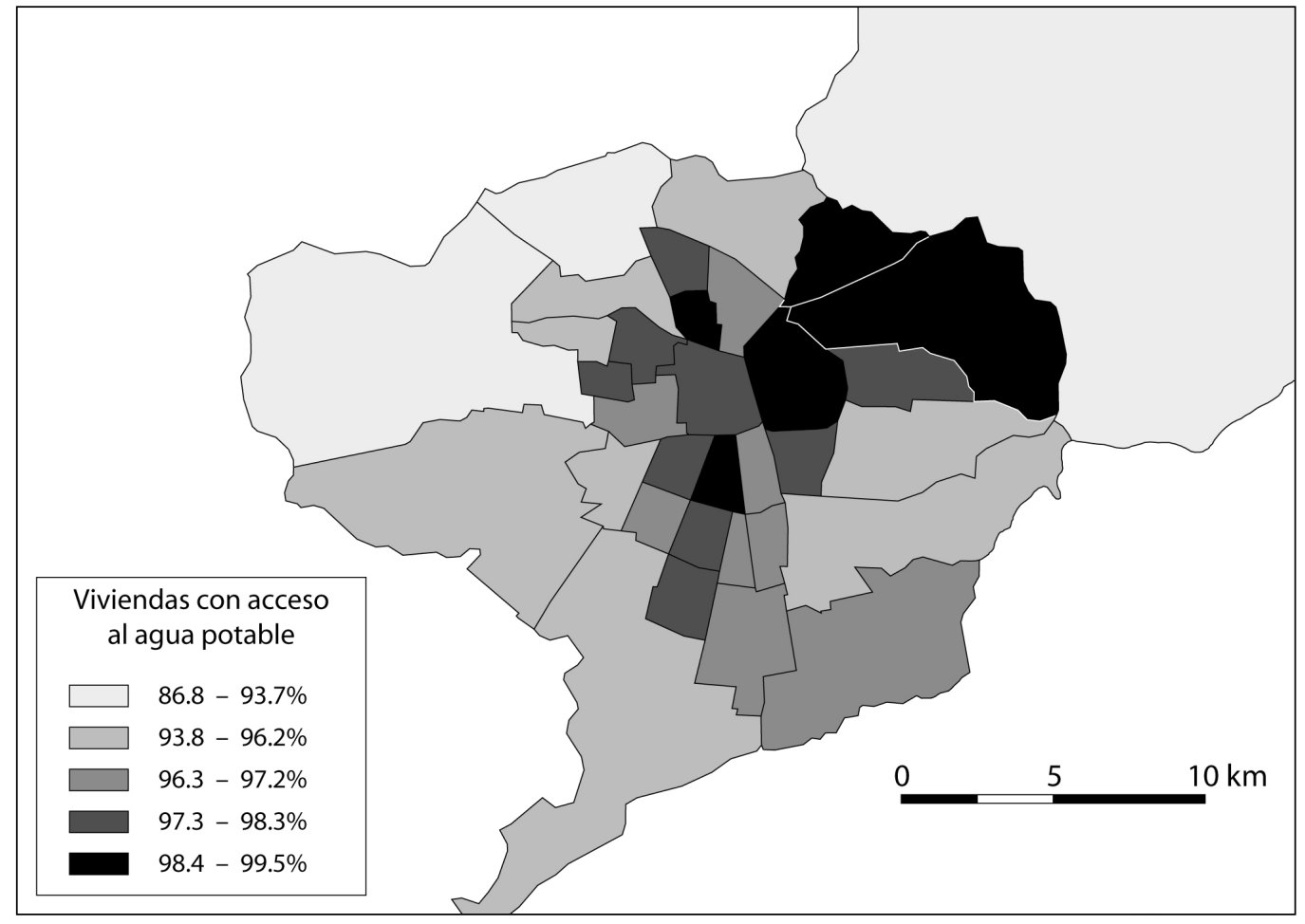

Fuente: Elaboración propia. 
Mapa 3. Tasas de acceso de las viviendas al alcantarillado en los municipios del Gran Santiago, 1982.

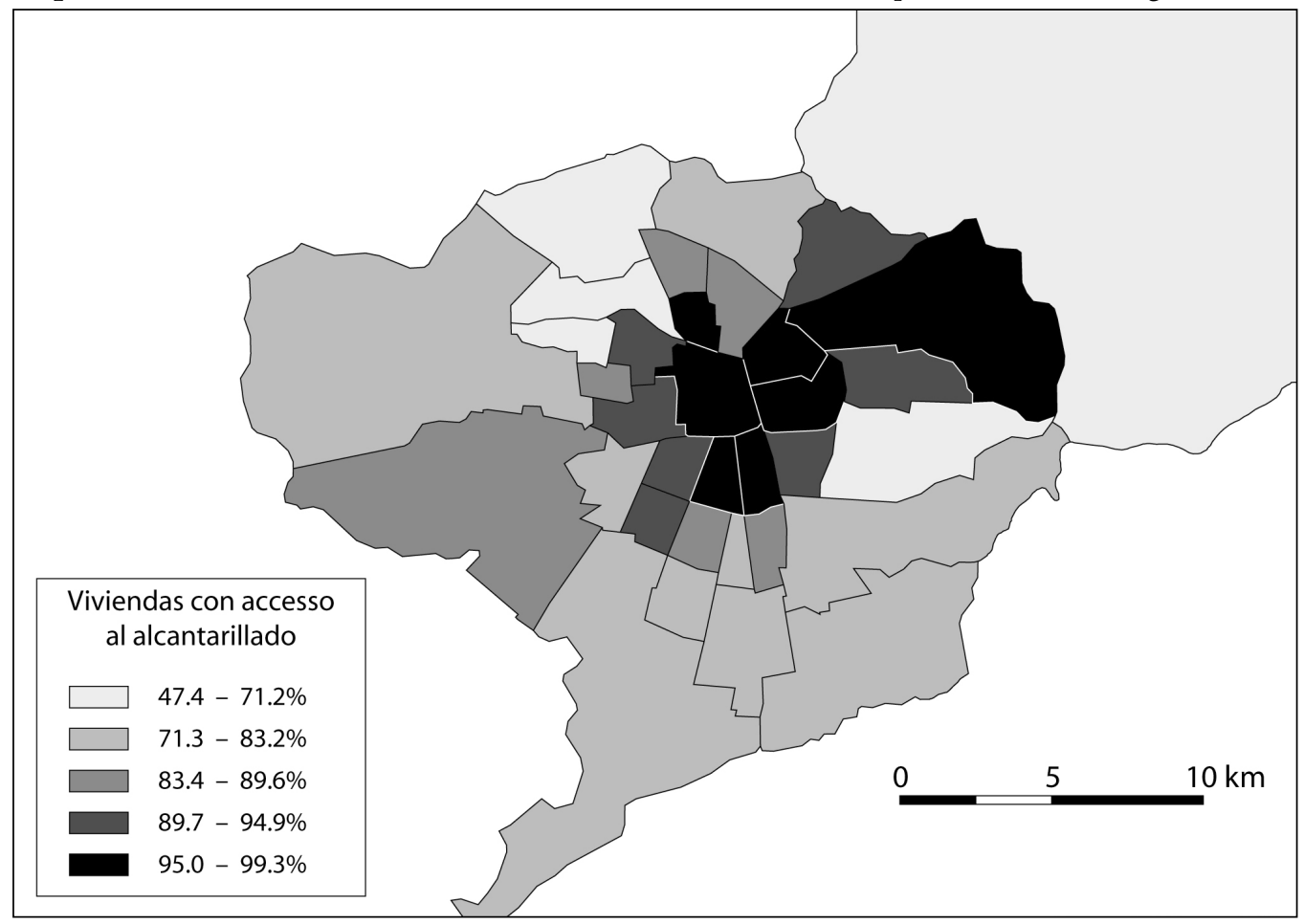

Fuente: Elaboración propia.

Entre 1982 y 1992, el número de viviendas conectadas a la red de agua potable sube un 38,6\% en el Gran Santiago, pasando de 796.000 a 1.100 .000 en diez años. De esta manera, la tasa de acceso a la red de agua alcanza un 99,1\%, contra un 83\% en 1970 y un 97\% en 1982 (INE, 1970, 1982, 1992). Así, podemos señalar una paradoja en la política de la vivienda chilena de los ochenta. Esta última conduce simultáneamente a un incremento del nivel de segregación socio-espacial y a una clara mejora del acceso a los servicios de agua y saneamiento. Si bien la política de la vivienda explica en gran medida la recuperación de la situación inicial de los ochenta, no permite entender por si misma el esfuerzo que fue realizado para conseguir el crecimiento de un 38\% del número de viviendas entre 1982 y 1992 . Porque, si bien la aplicación de la ley de urbanismo permitió conectar cada nueva vivienda a la red primaria del distribuidor de agua, la empresa debía por su parte realizar inversiones sustanciales para suministrar las nuevas zonas urbanizadas y ofrecer la cantidad de agua suficiente. Entonces, ¿cuáles fueron las condiciones técnicas y económicas que permitieron al sistema de distribución de agua enfrentar el crecimiento urbano?

\section{Primera reforma del servicio de agua y reactivación de la politica de inversión}

La primer gran reforma del sector agua-saneamiento data de 1977 con la creación del SENDOS (Servicio Nacional de Obras Sanitarias), reagrupando el conjunto de servicios del sector, hasta entonces dispersos en varios ministerios, bajo la tutela reforzada del Ministerio de Obras 
Públicas (MOP). Así, entre 1977 y 1989, el SENDOS es encargado de la administración y explotación de las redes de agua potable y de saneamiento en todo el país, a través de once direcciones regionales. Solo las regiones de Santiago y de Valparaíso permanecen gestionadas por empresas autónomas de derecho público (EMOS y ESVAL). Para ambos casos, el SENDOS actúa como ente regulador, definiendo las estructuras tarifarias, estableciendo las normas, controlando los presupuestos y los resultados (Aguas Andinas, 2000).

Desde 1977, junto a la creación de EMOS, el área urbana del Gran Santiago es abastecida por cinco distribuidores. En 1985, EMOS suministraba al 88\% de la población, en 33 de los 34 municipios, con la excepción de Maipú y de algunos sectores de los municipios de Cerrillos, de Estación Central y de Las Condes. EAPAM, servicio del municipio de Maipú, suministra a la totalidad de ese municipio, así como a un sector importante del municipio de Cerrillos y a una pequeña parte del municipio de Estación Central, es decir, al 5,9\% de la población del área urbana en 1985. Finalmente, se debe mencionar la existencia de tres servicios privados, siendo el más importante la Empresa de Agua Potable Lo Castillo (EAPLOC), que alimenta al 5,8\% de la población del área urbana en 1985, específicamente, a ciertos barrios ricos asentados en el municipio de Las Condes y de Lo Barnechea.

Desde 1977 y hasta en 1989, la estructura tarifaria de EMOS se reformó progresivamente, permitiendo un autofinanciamiento de la explotación y de las inversiones corrientes (reemplazo de las redes, amortizaciones y reservas). Esta reforma solo fue posible gracias a la creación de una empresa integrada como EMOS, que controla el agua y el saneamiento de una gran mayoría del territorio metropolitano, lo que le permite realizar una clara evaluación de las necesidades de inversión. El primer objetivo de la reforma tarifaria fue fijar precios para el autofinanciamiento contable de la empresa, por lo tanto, sin fijar objetivos de rentabilidad económica. Las tarifas se basan en un doble esquema de tarificación según los costos completos y los subsidios, cruzados entre varias categorías de consumidores. Esos subsidios son calculados en función del volumen de consumo de los clientes. El postulado inicial es que los hogares pobres controlan más su consumo que los hogares más acomodados, dadas sus fuertes restricciones presupuestarias (Icaza y Rodríguez, 1988, p. 40). Así, se pueden distinguir tres bloques de tarifas. En el primer bloque, el más subvencionado, que se aplica a los clientes que consumen menos de $15 \mathrm{~m}^{3}$ por mes, el total del consumo es eximido de pago. El segundo bloque -entre 16 y $31 \mathrm{~m}^{3}$ - consiste en una tarifa reducida para los 15 primeros $\mathrm{m}^{3}$ consumidos, seguido de una tarifa normal. Los clientes pagan entonces el agua a su coste real en este caso. El tercer bloque apunta a los clientes que consumen entre $31 \mathrm{~m}^{3}$ y $45 \mathrm{~m}^{3} \mathrm{al}$ mes, para quienes es aplicada una tarifa superior en el total del volumen consumido, permitiendo así la subvención del primer nivel de consumo.

La tarificación por bloques crecientes vuelve compleja cualquier evaluación de la evolución de las tarifas a lo largo de la década de los ochenta, debido a que se dispone de pocos datos en los archivos de la empresa. En un informe del 2000, Shirley et al. (p. 34) proponen un cálculo simplificado de las tarifas mostrando el importe total facturado para los volúmenes de agua distribuidos, en dólares de 1996. Según ese cálculo, los precios medios del agua pasaron de $0.19 \$ U S / \mathrm{m}^{3}$ en 1981 , a $0,08 \$$ US en 1985 , y a $0,11 \$$ US en 1988 , ultimo año antes de la segunda reforma profunda del sector. 
A partir de la reforma de 1977, la estructura de ingresos de la sociedad EMOS se transformó profundamente. La parte de los ingresos totales procedentes de la facturación de los servicios de agua y de saneamiento pasó del $50 \%$ en 1979 , al $70 \%$ en 1982, y al 90,5\% en 1984. Así, a partir de 1980, el principio de autofinanciamiento se aplica a EMOS, aunque no fue contemplado en la ley hasta 1989. Además del producto de la facturación de servicios de agua y saneamiento, el resto de los ingresos procedía de las inversiones realizadas por la empresa con sus fondos propios, así como de un préstamo de \$26 millones del Banco Mundial (US\$, 1981), otorgado para el periodo 1980-1987. A partir de 1981, EMOS inició con el apoyo del Banco Mundial un programa de inversión con el fin de extender y mejorar la accesibilidad a la red de agua potable: se refiere al Programa de Mejoramiento Integral del Abastecimiento de Agua Potable de la Región Metropolitana. Los objetivos principales de este programa fueron mejorar el abastecimiento de la población del Gran Santiago, tanto a nivel cualitativo como cuantitativo. Este propósito general buscaba el incremento de la capacidad de producción -nuevos recursos, reforzamiento de la capacidad de tratamiento de las aguas de superficie, desarrollo de la red de transporte y de distribución-, la mejora de la eficacia de la gestión de la red y del servicio -reducción de las pérdidas, del nivel de endeudamiento, de los costos operacionales- y la mejora de la calidad de la red existente -reemplazo de conductos y adaptación de la capacidad de las redes a la demanda de las nuevas zonas urbanizadas-. La reforma de las tarifas de la empresa, el incremento de su capacidad de inversión y el apoyo del Banco Mundial permitieron entonces a EMOS suministrar un recurso suficiente y extender su red de distribución al mismo ritmo que la urbanización.

Pocos datos e información son accesibles sobre el nivel de accesibilidad social al servicio (impagos e interrupciones de servicio) a lo largo de los ochenta. El único estudio serio sigue siendo el trabajo de Ana Icaza y Alfredo Rodríguez (1988) que colecta y analiza por primera vez las tasas de impagos e interrupciones. Con el fin de evitar la inclusión de simples demoras de pago, podemos enfocarnos sobre los impagos de más de tres meses. Tres meses corresponden también al periodo después del cual, desde 1977, la empresa está autorizada a cortar el suministro de agua a sus clientes endeudados. La tasa de endeudamiento de más de tres meses baja entre 1980 y 1987, pasando del 11,2 al 7,5\%. Esa baja puede explicarse por el reforzamiento del dispositivo de interrupciones más allá de tres meses de demora, así como por la instauración de convenios de pago, cuya tasa pasa del 2,3 al 7\% entre 1980 y 1987. Por el contrario, podemos poner de manifiesto una clara alza de las tasas de endeudamiento de menos de tres meses que pasan del 13 al 20\%. El efecto límite entre más o menos de tres meses de demora se explica por la firma de convenios de pago que permiten distribuir la deuda y por el papel disuasivo de las interrupciones.

\section{Redes domiciliarias, promoción inmobiliaria y expansión urbana: Santiago en vías de fragmentación}

La generalización progresiva de las redes de agua potable desde la mitad de los setenta tiene que ser evaluada con respecto al crecimiento de la población y del número de viviendas. En efecto, después de un largo periodo de desarrollo entre 1950 y 1980, el ritmo de crecimiento demográfico de la metrópolis chilena se estabiliza a lo largo de los ochenta. Las tasas anuales de crecimiento demográfico se elevan al 5\% durante los cincuenta, 4,6\% durante los sesenta, 
3,5\% durante los setenta y solo el 1,8\% durante el periodo 1982-1992. Sin embargo, si bien el crecimiento demográfico se estabiliza, ¿qué ocurre en cuanto al crecimiento urbano? ¿Cómo evolucionó el crecimiento urbano, en paralelo con el desarrollo de las redes?

\section{Un crecimiento urbano limitado hasta en 1985}

El estudio de la morfología del crecimiento urbano nos invita primero a poner de manifiesto que hasta 1990, la expansión más rápida del área urbana fue registrada a lo largo del periodo 1960-1975 (Petermann, 2006, p. 214). Esa ocupación del suelo fue tanto la consecuencia de la producción privada como de la producción pública de viviendas. En efecto, los programas sucesivos de vivienda social, y particularmente bajo el Gobierno de Allende, se localizaron en la periferia de la zona urbanizada, en la primera y segunda corona, con la excepción de la zona noreste donde pocas viviendas fueron construidas.

En 1979, con la promulgación de la nueva Política Nacional de Desarrollo Urbano (PNDU) por el Gobierno de Pinochet, el modelo liberal se aplicó a la planificación urbana, gracias a una apertura del mercado inmobiliario. Desde entonces, el Estado liberal buscó dejar importantes márgenes de maniobra al mercado inmobiliario y favorecer un desarrollo urbano extensivo para la aglomeración. Se afirmó claramente que el suelo no era un recurso limitado y que la función del mercado es encontrar el tamaño óptimo de la ciudad y definir el empleo del suelo (Larraín, 1994). Así, el Gobierno Militar modificó el Plan Regulador Intercomunal para Santiago (PRIS) de 1960 con tres medidas estrellas:

- la supresión de los antiguos límites de la urbanización;

- la duplicación de la superficie abierta a la urbanización, pasando de 35.000 a 100.000 há;

- y la disminución de impuestos para las transacciones inmobiliarias.

En concreto, las 100.000 há urbanizables no correspondían exactamente a un área indiferenciada en términos de costos de urbanización. El decreto de 1979 introdujo en efecto dos zonas: i) una zona urbana en la cual la urbanización se autoriza y las autoridades públicas son obligadas a invertir para viabilizar los terrenos, equiparlos y suministrar un servicio público; ii) una zona de expansión urbana que autoriza la urbanización privada sin que el Estado se comprometa a construir las infraestructuras y a integrar las nuevas urbanizaciones en el nuevo perímetro urbano (Petermann, 2006, p. 218). El perímetro de la zona urbana permanecía relativamente restringido ya que correspondía exactamente a la zona urbanizada, integrada al antiguo límite urbano de 1975. En el seno de esa zona los promotores no debían financiar las infraestructuras, solo la conexión a las redes de distribución de los operadores. El mapa del crecimiento urbano entre 1979 y 1985 propuesto por Alexandra Petermann enseña claramente que la urbanización fue relativamente débil más allá del área urbana y en el seno del área de expansión a lo largo del periodo. Así, la liberalización total del mercado inmobiliario, y la idea del "Santiago sin límites" representa más una ambición política de los liberales chilenos que una realidad al inicio de los ochenta. Ese crecimiento ralentizado en un contexto de liberalización inmobiliaria puede ser imputado a tres factores: i) la producción de viviendas sociales públicas, localizadas en la periferia sur de la aglomeración, fue prácticamente abandonada a 
partir de 1978; ii) la crisis económica que alcanza Chile a partir de 1982 y la recesión limitan fuertemente la inversión inmobiliaria; iii) las restricciones de infraestructura que pesan sobre la urbanización en el área de expansión urbana bloquean la urbanización en esa zona.

\section{Servicios secesionistas para las clases acomodadas}

Combiene matizar el escaso movimiento de desarrollo urbano entre 1980 y 1985, con el fuerte crecimiento urbano privado en el cuadrante noreste de la aglomeración, en el seno del perímetro de "expansión urbana". Excluidos del límite urbano legal entre 1960 y 1979, esos barrios descentrados de los municipios de Vitacura, Las Condes y Lo Barnechea disponían para su localización de un fuerte capital social, simbólico y paisajístico. Los promotores inmobiliarios pudieron asegurarse las inversiones y la distribución de servicios apoyándose en los distribuidores privados de agua. El sistema de zona de expansión excluyendo el suministro público en servicios esenciales no frenó entonces el asentamiento de los hogares de las clases más acomodadas a las afueras de la zona urbanizada.

La empresa Lo Castillo, fundada en 1947 para suministrar a los nuevos barrios de Las Condes, contaba varios centenares de consumidores a principios de los cincuenta, cerca de 7.000 en 1968, 42.000 en 1983, 65.000 en 1994 y 107.469 en 2005 (Danière et al., 1994 para 1968, 1983 y 1994; Superintendencia de Servicios Sanitarios, SISS, 2005). En los sesenta y después a principios de los ochenta, siguiendo la delimitación de la nueva área de "expansión urbana”, dos empresas suplementarias fueron creadas para suministrar nuevas urbanizaciones de Las Condes. La primera, Empresa de Agua Potable Villa Los Dominicos, contaba 1.013 clientes en 1985, y la segunda, Aguas Manquehue, contaba 306 clientes (INECON en Icaza y Rodríguez, 1988, pp. 13-18). Estos tres distribuidores fueron creados por inmobiliarias con el fin de viabilizar las zonas de construcción, y aplicaron tarifas más elevadas que las de EMOS, o de Maipú, pero sin un esquema en bloques crecientes y sin un dispositivo de perecuación con el resto del área metropolitana. La diferencia de tarifa se explicaba ante todo por el costo más elevado del suministro de los barrios altos de la ciudad, así como por la baja densidad. Si bien puede parecer normal que los habitantes de los barrios más acomodados soporten el costo de las nuevas urbanizaciones, conviene poner de manifiesto que esa fragmentación redujo el impacto de los subsidios cruzados a lo largo de los ochenta. Las tres empresas privadas de distribución de agua del este de la capital reunían el 80\% de los hogares más acomodados de la aglomeración, en 1988 (Rosenfeld, 1990, p.7). Eso significa que sólo el 20\% de los clientes de categorías sociales superiores participaban del sistema de subsidios cruzados de EMOS o de Maipú.

Para las empresas privadas los costos de conexión son mucho más elevados, dependiendo de la longitud de la red a desplegar, de su diámetro, del tipo de material, de la mano de obra necesaria y del volumen de consumo previsto. Así, por ejemplo, en el área de servicio de EMOS, el costo de una nueva conexión con un contador de $15 \mathrm{~mm}$ de diámetro se elevaba a 1.402 pesos-1987, con un impuesto del Estado de 2.750 pesos-1987. Por su parte, Empresa Lo Castillo facturaba una tarifa de conexión siempre comprendida entre 25.000 y 50.000 pesos (Icaza y Rodríguez, 1988). Con un costo de conexión muy elevado, los distribuidores privados ejercían un control 
de la ocupación del suelo contribuyendo a subir un poco más el costo de construcción en las zonas donde la valorización del inmobiliario era particularmente fuerte.

Hasta en 1977, las empresas privadas de distribución de agua no fueron sometidas a una regulación formal (Morandé, 1997, p. 8). Después las tarifas fueron definidas por el Ministerio de Economía sin regla de tarificación preestablecida. En 1993, el director de la Empresa de Agua Potable Lo Castillo, Alejandro Dussaillant (entrevistado por A. Danière, 1994, p. 13), afirmó que los precios regulados no habían permitido cubrir los costos completos de suministro de los servicios de agua y de saneamiento. Las empresas Lo Castillo, Manquehue y Villa Los Dominicos no quebraron porque se aprovecharon de las subvenciones presupuestarias del agua otorgadas por los urbanizadores, gracias a los ingresos procedentes de la venta de terrenos y edificios.

\section{Las presiones sobre la gestión de los servicios urbanos}

Los límites establecidos por la nueva política urbana emprendida en 1979, en términos de especulación y de segregación, condujeron rápidamente al Gobierno a revisar sus modos de intervención. En 1985, el Ministerio de la Vivienda (MINVU) suprimió el área de expansión urbana definida en 1979, estableciendo esta vez el objetivo de densificación, entendiendo que el suelo es un recurso escaso y que los costos de suministro en infraestructuras de las nuevas viviendas eran mucho más elevados en el área de expansión urbana que en la zona urbanizada (MINVU en Petermann, 2006, p. 222).

En el contexto de un crecimiento urbano ralentizado, entre 1980 y 1987, el lobby inmobiliario desarrolló un papel determinante a favor del establecimiento de una agenda para una reforma profunda del sector sanitario, preparada en 1988 y validada en 1989, poco antes de la caída del Gobierno Militar. Los problemas de financiamiento y de capacidad de inversión eran muy serios en el caso de EMOS. El Banco Mundial, primera institución en ejercer presión a favor de la reforma, ponía así de manifiesto las dificultades financieras de la sociedad EMOS en 1986 (Shirley et al., 2000): el presupuesto de la sociedad fue ligeramente mejorado entre el inicio de los ochenta y 1987, las tarifas de autofinanciamiento contable permanecían bajo el costo marginal de largo plazo, la tasa de rentabilidad de los activos solo era del $2,7 \%$. A nivel político, el apoyo más ferviente provenía de los beneficiarios potenciales de los efectos de la reforma. Según Shirley et al. (2000, p. 16), los inversores privados eran el apoyo más importante al proyecto, inversores que se aprovecharían de nuevos contratos como resultado del incremento de la capacidad de inversión, de fuertes presiones para la privatización de la empresa EMOS, y de los posibles desarrollos del sector inmobiliario. 


\section{La reforma de 1989: una gestión privada con capitales públicos}

Aparte del lobby inmobiliario, la reforma de 1989 se benefició de otro apoyo muy importante: el del Banco Mundial. Según la antigua directora de EMOS, Raquel Alfaro, bajo el mando de Pinochet, a partir de 1986, el Banco Mundial condicionó la entrega de un nuevo préstamo a la puesta en obra de una reforma estructural de EMOS ${ }^{4}$. Gracias a la reforma, desde 1989 y sobre todo entre 1990 y 1994, la empresa se benefició de un préstamo de 60 millones de dólares americanos (US\$ de 1986), mientras que el primer préstamo de 1980 se limitaba a un importe de $\$ 26$ millones (US\$ de 1980).

\section{Un nuevo marco reglamentario y de gestión}

La reforma de 1989 debía, en primer lugar, permitir el inicio del proceso de privatización de EMOS, fijando a la empresa restricciones de financiamiento, de rentabilidad y de eficacia idénticas a las de los distribuidores privados. De hecho, la privatización del sector del agua potable no aparecía como una prioridad debido a su menor rentabilidad respecto a las privatizaciones de las telecomunicaciones y de la electricidad, que habían significado al Estado un ingreso de US\$ 540 millones y US\$220 respectivamente a principios de los ochenta. El valor de EMOS fue estimado en unos US\$ 150 millones $^{5}$ durante el proceso de reforma de 1989 y el Gobierno de Pinochet sólo pensaba privatizar la empresa varios años más tarde, convencido de su victoria en el plebiscito de 1989. Antes de las votaciones, el Gobierno Militar ya había emprendido negociaciones con varios inversores potenciales, en particular españoles (Shirley et al., 2000, p. 20). Pero antes de las elecciones, Aylwin había manifestado que las empresas de servicio público ya no deberían ser privatizadas y cualquier proyecto del sector sanitario fue enterrado hasta que el presidente Eduardo Frei inició nuevas reformas (1994-2000).

A pesar del abandono del proyecto de privatización, la reforma contable y de gestión no fue modificada por el gobierno de Aylwin. Según la antigua directora de EMOS, Raquel Alfaro, la adopción definitiva del nuevo marco de regulación sólo unos meses antes de la caída del Gobierno de Pinochet representaba una oportunidad para el nuevo gobierno democrático: este podía imputar esa reforma impopular al régimen anterior y a la vez beneficiarse de sus efectos positivos en términos de resultados y eficacia económica. Aprovechándose de los efectos de las subidas de tarifas y del reforzamiento de los resultados de la empresa, el Estado-accionista

\footnotetext{
4 A la inversa de la política de la vivienda, no hubo un conflicto importante entre el Gobierno Militar y el Banco Mundial sobre la reforma del sector del agua y alcantarillado. De hecho, como lo subraya Raquel Alfaro, directora de EMOS entre 1990 y 1997, la antigua directora de EMOS bajo el Régimen Militar, María Josefina Bolelli, los representantes del Gobierno Militar y el Banco Mundial coincidían sobre la necesidad de reformar EMOS y alcanzar tres objetivos complementarios: la universalización del acceso al alcantarillado en los barrios más pobres, la definición del precio que permitiera la autofinanciación de la empresa y el reforzamiento de la capacidad de inversión con fondos propios. Esa reforma de casi privatización exigida por el Banco Mundial se conjugó con los proyectos de reformas económicas de Pinochet, así como con los ideales de acceso universal promovidos por los ingenieros de la empresa pública.

5 Siguiendo esa segunda reforma de la gestión y el reforzamiento de los resultados y de la rentabilidad de EMOSSA, la privatización parcial de la empresa generó 965 US\$ millones para el Estado chileno en 1999, durante una nueva fase de privatización de los servicios urbanos.
} 
se benefició con cerca de US\$75 millones, dividendos procedentes de EMOS-SA entre 1990 y 1994 (Shirley et al., 2000). Enmarcada en el movimiento de democratización que disfrutó Chile desde 1990, la reforma de 1989 y las subidas consecutivas de precio provocaron la enérgica oposición de movimientos de vecinos y consumidores. Más tarde, a partir de 1995, el movimiento de consumidores en fase de consolidación (a través de la Organización de Consumidores y Usuarios de Chile, ODECU) denunció con fuerza la falta de consideración de las repercusiones de las subidas de precio y de forma más general, la falta de participación de los consumidores en el proceso de regulación: "el marco regulatorio en el sector sanitario [...] no contempla la participación de los consumidores en ninguna fase del mecanismo regulatorio, no está contemplada en el proceso de fijación de tarifas, ni tampoco en el procesamiento de quejas recepcionadas por la SISS" (ODECU, 1998, p. 89). Desde entonces, el movimiento de los consumidores chilenos se comprometió a defender a los usuarios más modestos exigiendo que criterios de equidad social sean integrados en las formulas de cálculo de los precios, demanda que nunca fue atendida.

El contenido de la reforma se asentaba sobre dos transformaciones principales: la creación de una autoridad de regulación nacional disociada de las intervenciones del Estado-accionista; el reforzamiento de los criterios de resultados y la refundición del modelo tarifario.

Primero, con el fin de separar las funciones de regulación política y de gestión, que el Ministerio de Economía siguió asumiendo hasta la privatización de 1999, respecto de las funciones de reglamentación técnica, económica y tarifaria, una nueva autoridad independiente fue creada por la Ley 18.902 de 1990: la Superintendencia de Servicios Sanitarios (SISS). Aparte de las actividades de pilotaje y de control que iban a ser conducidas por la SISS de ahora en adelante, once empresas regionales públicas y autónomas fueron creadas para sustituir a las antiguas direcciones regionales del SENDOS. La SISS dispone, entonces, de poderes de reglamentación equivalentes a los de otros reguladores - definición de las tarifas, control de los estándares técnicos, atribución de concesiones, control de calidad de los afluentes, etc.

A nivel tarifario, el proceso de fijación de precios fue profundamente revisado. Las tarifas de autofinanciamiento contable eran antes relativamente estables y las alzas poco frecuentes. El esquema de tarifas es ahora un modelo de autofinanciamiento que toma en cuenta los proyectos de desarrollo de la empresa, con una tarifa lineal, cualquiera sea el volumen consumido, anulando así la tarificación por bloques. Esta definición de tarifas es realizada por expertos independientes sobre una empresa ficticia, incorporando el conjunto de los costos teóricos de funcionamiento y de inversión en el agua y el saneamiento en la región del Gran Santiago. Luego, esta empresa teórica es puesta en comparación con las estructuras de costo presentadas por EMOS, teniendo en cuenta su plan de desarrollo. Esta nueva fórmula tarifaria es en principio incitativa porque si EMOS es más eficaz que la empresa modelo se beneficiará de márgenes financieros mas elevados. Además, esa fórmula tarifaria fomenta las inversiones, porque cada nuevo activo -como una planta de tratamiento de aguas servidas o nuevos colectores- serán integrados en la empresa modelo, lo que significa que las tarifas siguen las inversiones efectivamente realizadas por la empresa EMOS a partir de 1990. 
Así, la capacidad de inversión de EMOS mejoró gracias a las fuertes subidas de precio. Entre 1989 y 1990, el precio medio del agua en Santiago había ya subido un 50\% en un año, y entre 1989 y 1996 el precio medio para la empresa EMOS subió del 77\% (en pesos de 1995). Al final de 1998 el precio medio había prácticamente doblado (Gómez-Lobo, 2003). Descontando los préstamos del Banco Mundial, las inversiones contratadas por EMOS con sus fondos propios pasaron de US\$ 6 millones al ańo, entre 1987 y 1989, a cerca de 20 millones en 1990, 32 millones en 1991 y a 40 millones promedio al año entre 1992 y 1996 (US\$ de 1996) (Shirley et al., 2000).

\section{Efectos de la reforma en términos de accesibilidad social y espacial al servicio}

En cuanto a los efectos de la reforma, ésta permitió concluir la universalización de la red de alcantarillado y resolver los últimos puntos negros de la red del agua. Siempre al nivel espacial, el reforzamiento de la capacidad de inversión del distribuidor permitió a este último acompañar la reactivación del crecimiento urbano que se observó desde finales de los ochenta. A continuación se detallan los efectos de la reforma sobre la accesibilidad social al servicio.

\section{La culminación de la universalización del alcantarillado}

Los primeros efectos de la reforma de 1989 se refieren a la culminación de la universalización de la red de alcantarillado. Bajo el efecto de las subidas de precio y del segundo préstamo del Banco Mundial, y gracias a nuevas inversiones, las desigualdades de acceso al saneamiento, aún observables en 1992, entre municipios más acomodados y municipios centrales, por un lado, y municipios de renta baja, por el otro, fueron rápidamente resueltas. La tasa de acceso a alcantarillado correspondiente a un 98\% fue así alcanzada en 1996.

Las viviendas sin conexión a principios de los noventa fueron a menudo construidas por los propios habitantes y no respetaban las obligaciones de conexión a las redes de base, incluidas en la Ley de Urbanismo. En ese caso, la ley prevé que los municipios deben paliar la falta de redes de distribución realizando los trabajos necesarios. Sin embargo, los municipios pobres, donde estaban localizadas estas viviendas informales, no disponían de medios financieros suficientes como para realizar las conexiones. EMOS creó, entonces, una unidad especial para completar los eslabones que faltaban a la red. Esta política se apoyó en el Fondo Nacional de Desarrollo Regional (FNDR) así como en fondos procedentes del segundo préstamo del Banco Mundial. En ese caso, el municipio y EMOS financiaban cada uno un tercio de las obras, siendo el último tercio pagado por los consumidores involucrados. EMOS estima que cerca de 10.000 familias (es decir, alrededor de 50.000 personas) se beneficiaron del acceso al agua potable y al saneamiento gracias a esas iniciativas. Estas últimas medidas permitieron resolver en parte el 3\% de déficit en conexiones que presentaba la ciudad, logrando cubrir al total de la población desde 1994 (Alfaro, 1996, p. 8). 
Mapa 4. Tasas de acceso de las viviendas al agua en los municipios del Gran Santiago, 1992.

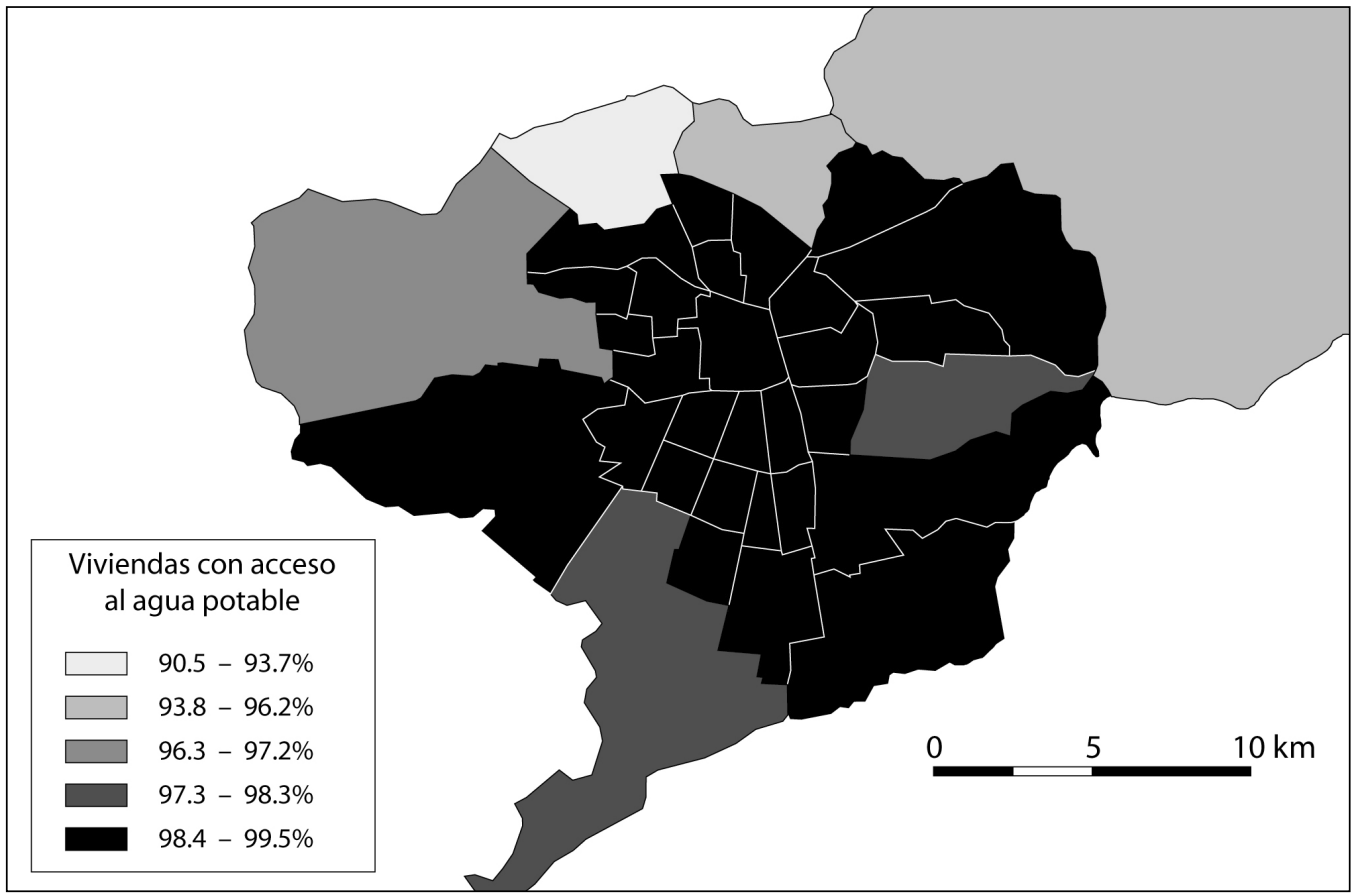

Fuente: Elaboración propia.

Mapa 5. Tasas de acceso de las viviendas al alcantarillado en los municipios del Gran Santiago, 1992.

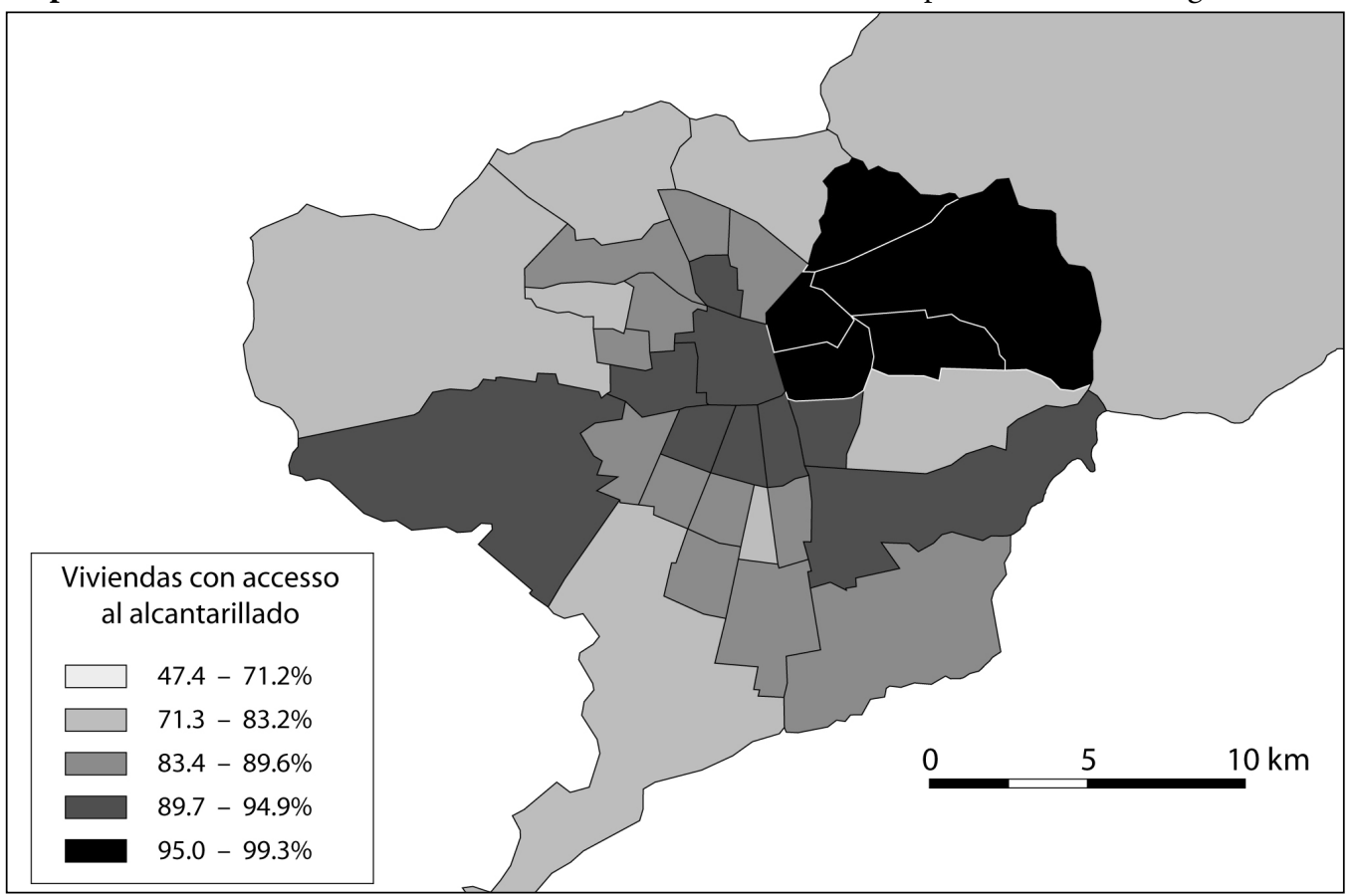

Fuente: Elaboración propia. 


\section{La aceleración del crecimiento urbano}

Además de solucionar los problemas de inaccesibilidad, EMOS consiguió enfrentar el fuerte crecimiento urbano de la aglomeración a partir de finales de los ochenta. Desde la segunda mitad de esta década, el crecimiento se verá apoyado por una reactivación de la economía chilena así como por la nueva política de gestión del agua y del saneamiento que conduce a las autoridades públicas a viabilizar un mayor número de terrenos. Entre 1986 y 1995, el crecimiento urbano de origen público y privado -compuesto por nuevas viviendas sociales del programa viviendas básicas y, sobre todo, de nuevas viviendas privadas- se localizará de forma uniforme en el conjunto de la periferia, en los márgenes de la urbanización (Petermann, 2006, p. 223). Entre 1991 y 2000, la zona urbanizada creció más que 12.000 há, pasando de 49.347 a 61.396 há, donde el $41 \%$ del crecimiento tenía vocación residencial (Ducci y González, 2006, p. 125).

Esta potencialización entre el desarrollo de redes y el crecimiento urbano no debe, sin embargo, sobreestimar la influencia de las infraestructuras en el inicio de este proceso que fue ante todo económico y político. Como lo pone de manifiesto Oscar Figueroa: "la asociación de las redes de servicios y el desarrollo urbano, que ha sido de larga data, se manifiesta en este caso a través de las funciones de soporte de los servicios, que reproducen las condiciones para el crecimiento urbano y permiten que éste se despliegue sin contratiempos" (2004, p. 271).

\section{La disminución de los impagos}

Como lo hemos puesto de manifiesto, la reactivación de las inversiones de EMOS a partir de 1990 se produjo con el costo de fuertes alzas de tarifas. Según la SISS, estas alzas no afectaron de la misma manera a todas las categorías de consumidores. Los usuarios cuyo consumo era de menos de $10 \mathrm{~m}^{3}$ por mes vieron su factura subir un 71,9\% cuando se modificó la formula de tarifas en 1991; las facturas de las personas que consumían menos de $15 \mathrm{~m}^{3}$ solo fue aumentada un 41,7\%; y para aquellos que consumían menos de $20 \mathrm{~m}^{3}$, el alza fue de solo un 29,2\%. En 1998, la Encuesta de Presupuestos Familiares calculó que el valor promedio de las facturas representaba el 1,14\% del presupuesto mensual de un hogar (INE, 1998), pero que ese importe alcanzaba el 2,35\% del presupuesto del primer quintil de rentas.

Según los datos que disponemos, las alzas en las tarifas no tuvieron un efecto directo sobre el consumo en Santiago. La elasticidad de la demanda fue bastante baja, debido a las fuertes subidas de precio observadas. De hecho, los informes anuales de EMOS presentan una ligera caída del consumo anual de los clientes (y no de los residentes), que pasó de 34,1 $\mathrm{m}^{3}$ en 1990 a $31,1 \mathrm{~m}^{3}$ en 1996 . Esta caída se puede igualmente explicar por la relación del número de personas por hogar y por vivienda a lo largo del mismo periodo. En complemento, a escala de la Región Metropolitana, las estadísticas del INE atestiguan un ligero decremento de la demanda por habitante: entre julio del 1992 y julio del 1998, el consumo por habitante pasó de 90 a $87 \mathrm{~m}^{3}$ por habitante al ańo. Este promedio, a escala metropolitana no es significativo, ya que puede esconder importantes diferencias de consumo entre sectores. Así los datos de la SISS demuestran que en 1996, el consumo en el municipio de Las Condes (Empresa Los 
Dominicos) se elevaba a $148 \mathrm{~m}^{3}$ por servicio, frente a los $31,3 \mathrm{~m}^{3}$ para EMOS y a los 28,5 $\mathrm{m}^{3}$ para el servicio municipal del modesto municipio de Maipú.

Ahora, los efectos de las primeras alzas de precio sobre la inaccesibilidad social al servicio y los impagos no se hacen sentir. Es así como, las tasas de endeudamiento de más de tres meses bajaron entre 1986 y 1993, de un 8 a un 4,3\%, con una clara inflexión entre 1991 y 1992 cuando la tasa de endeudamiento disminuye cerca de $1,5 \%$.

Figura 6. Tasa de endeudamiento de más de tres meses (1980-1993).

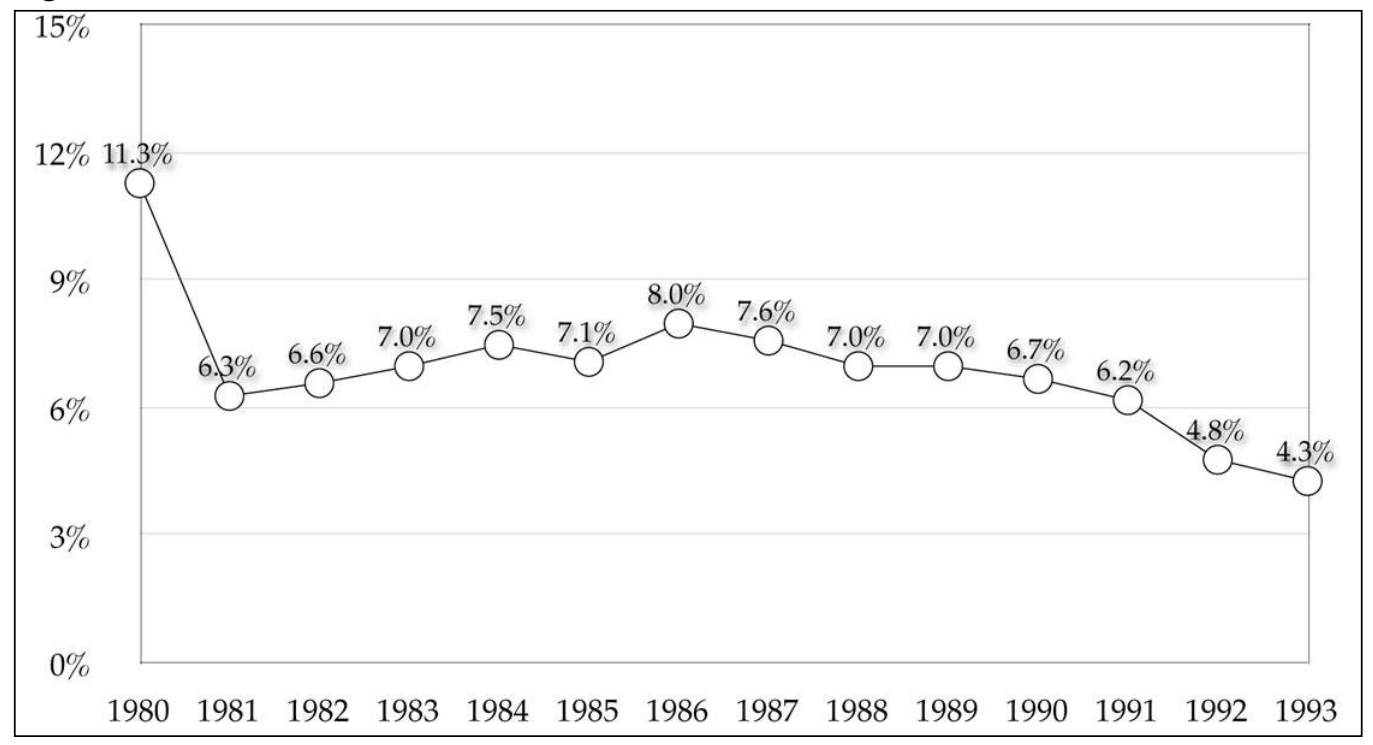

Fuente: Elaboración propia con base los datos de EMOS.

La disminución del nivel de endeudamiento se debe a la aplicación de una nueva subvención pública al consumo de agua potable a partir de 1989, en reemplazo del antiguo sistema de ayudas que proponía la gratuidad de los cinco primeros $\mathrm{m}^{3}$. A partir de 1990, es el Estado y el presupuesto público nacional que fue movilizado para apoyar el consumo de agua potable de los más pobres. Estas ayudas se incrementaron fuertemente en términos de presupuesto a lo largo de los noventa, ya que el presupuesto estatal destinado a ello pasó de \$207.000 en 1990, a casi 9 millones en 1995 y 14 millones en 1997 (Subsecretaría de Desarrollo Regional y Administrativo, Ministerio del Interior, 1997). El financiamiento de las ayudas aparece más equitativo que en el antiguo sistema de apoyo al pequeño consumidor, ya que, desde 1990, es sostenido por el presupuesto nacional y, por lo tanto, por los impuestos sobre la renta del trabajo de tipo progresivo (que varían entre 0 y $45 \%$ en función del tipo de ingreso).

Los subsidios chilenos al consumo de agua pueden ser calificados como output-based aids: su distribución e importe son fijados en función del status social del hogar. Esta decisión de escoger a priori a los beneficiarios genera cierta complejidad en la gestión de los subsidios. El Ministerio de la Planificación (MIDEPLAN) es encargado de la gestión global de dichos subsidios, definiendo anualmente la cantidad de ayudas para cada una de las regiones, incluida 
la Región Metropolitana de Santiago. Sólo entonces, los servicios regionales del Mideplan reparten los subsidios entre los municipios. Este reparto se realiza en función del ingreso medio de los residentes del municipio, definido a partir de una encuesta llevada a cabo cada cuatro años: la encuesta CASEN. Los municipios en función de ello escogen a los beneficiarios, los que deben dirigirse al distribuidor de agua, el cual recibe luego directamente el importe del subsidio por parte del Estado, y lo deduce del importe de la factura mandada al cliente.

El importe de los subsidios debe respetar dos condiciones: según las recomendaciones de la Organización Mundial de la Salud, debe resguardar que los hogares no gasten más del 5\% de sus ingresos en el pago de sus facturas de agua; además, no debe representar más de $15 \mathrm{~m}^{3}$ de consumo $\left(10 \mathrm{~m}^{3}\right.$ hasta 1991). El importe del subsidio es fijado al nivel regional en función de las tarifas aplicadas y del ingreso medio de los hogares; no varía en función del tipo de cliente. MIDEPLAN fija el nivel de consumo a subvencionar y calcula el precio de ese consumo en función de las tarifas del distribuidor regional. Después, empleando los datos de la encuesta CASEN, o sea el ingreso promedio de los hogares de la región, fija el número y sobre todo el importe del subsidio (Gómez-Lobo, 2000). En la Región Metropolitana, el porcentaje máximo de la factura a subvencionar fue fijado por MIDEPLAN en 50\% desde 1992.

La principal dificultad de gestión de las subvenciones se encuentra a la hora de definir los consumidores elegibles. Los cuatro primeros años de aplicación de los subsidios al consumo de agua potable, del 1990 al 1994, se caracterizaron por presentar importantes dificultades. En 1990, por ejemplo, la tasa de cobertura de los subsidios (número de subsidios otorgados/ número de subsidios propuestos) fue extremadamente baja (5,1\%) (MIDEPLAN, 1999).

Estas dificultades en el inicio obligaron a una reforma rápida del sistema. La Ley 19.059 del 31 de mayo de 1991 introduce importantes enmiendas: la prohibición de subvencionar a los usuarios que consumen más de $20 \mathrm{~m}^{3}$ por mes fue levantada; el volumen de consumo máximo a subvencionar pasó de $10 \mathrm{~m}^{3}$ a $15 \mathrm{~m}^{3}$. La revisión del sistema trajo efectos positivos directos sobre la tasa de distribución del subsidio. A lo largo del segundo semestre de 1991, en menos de cuatro meses, el porcentaje de subsidios distribuidos pasó del 14,1 al 41,9\%. Además, a partir de finales del año 1991, una unidad especial fue formada por EMOS para ir en la búsqueda de potenciales candidatos al subsidio en los barrios pobres de La Pintana, La Florida o de La Granja. Encubierta como acción social, este planteamiento permitió a EMOS mejorar la tasa de morosidad, en el mismo año que el precio del agua subió un 50\%. Gracias a ese conjunto de medidas, la tasa de distribución de los subsidios alcanzó un 75\% en diciembre de 1992, un $85 \%$ en 1994 y un $95 \%$ en 1997.

\section{Conclusión}

La historia de Santiago nos invita a discutir la tesis de la fragmentación por las redes (splintering urbanism) de Gramham y Marvin (2001), que tiende a oponer a un ideal moderno de integración territorial -promovido por servicios integrados, monopolísticos y de propiedad pública- un modelo contemporáneo de fragmentación, relacionado con el unbundling de las redes urbanas, la crisis financiera de las infraestructuras, las reforma liberales y el abandono del ideal de integración espacial en la planificación urbana. 
En 1995, al final del periodo estudiado, Santiago de Chile dispone de un servicio de distribución de agua y de saneamiento eficaz y universalmente accesible. Ese ideal moderno de infraestructura fue alcanzado sobre todo gracias a una política ofensiva de construcción de viviendas públicas bajo el gobierno de Allende, y gracias a la política de subvenciones para el acceso social a la propiedad bajo el gobierno de Pinochet. La política de vivienda también fue asociada a la erradicación violenta de los campamentos bajo el Gobierno de Pinochet.

Luego, la primera conclusión, es que la universalización del agua potable en Santiago fue producto de las políticas de la vivienda emprendidas por el Estado, y no de una política de servicio público llevada a cabo por las empresas públicas de redes. Si podemos hablar de modern infrastructure ideal (Graham y Marvin, 2001), en Santiago no fue la consecuencia de una supuesta época dorada de los servicios públicos, sino más bien de una política de vivienda. De esta manera, una modern infrastructure ideal puede ser tambien promovida por políticas urbanas y sociales, es decir, por la voluntad del Estado de universalizar el servicio, más que por una política de red o de servicio público en el sentido más estricto.

En segundo lugar, las políticas de vivienda y de desarrollo urbano fueron acompañadas de dos reformas sucesivas en la gestión del servicio, en 1977 y después en 1989; las que permitieron inversiones para primero poner a nivel la distribución de agua y después la red de alcantarillado. A pesar de haber sido una política urbana y social fuertemente discriminatoria, las redes de agua potable y de saneamiento se fueron universalizando de forma igualitaria, a la vez que seguían el crecimiento rápido del número de viviendas a partir de la segunda mitad de los ochenta. Con la introducción de un subsidio al consumo de agua potable, las reformas permitieron hacer solvente a una parte importante de la clientela modesta y disminuir sensiblemente la tasa de morosidad. Además, las nuevas modalidades de gestión de los servicios de agua iniciadas a partir de 1989 no incrementaron el nivel ya elevado de fragmentación institucional, sino más bien lo redujeron. Así, los procesos de privatización de la gestión de los servicios, de liberalización y de re-regulación no conducen automáticamente al unbundling de los servicios y de las redes, ni al deterioro de la calidad de servicios para los consumidores menos solventes.

Es así como, a partir del ejemplo de Chile, podemos formular una tercera objeción a la tesis del splintering urbanism (Graham y Marvin, 2001): un modelo de integración de un amplio territorio por medio de redes no es necesariamente sinónimo de integración social de los espacios urbanos. Al contrario, la integración de un amplio territorio a través de redes puede apoyar un proceso de fragmentación urbana cuyas raíces son ante todo políticas y fiscales. El ejemplo de Santiago nos enseña que la conjunción entre desregulación del suelo, extensión urbana y expansión de infraestructuras tiene efectos importantes en términos de fragmentación y de segregación. Esta observación valida las hipótesis propuestas por Stephen Graham y Simon Marvin sobre el peso de la extensión urbana en los procesos de fragmentación a través de las redes. El caso de Santiago, arquetipo de la ciudad liberal contemporánea, esclarece el papel estructurante que pueden ejercer las redes en un contexto de desregulación del suelo. Cuando ya no existen barreras a la urbanización, el área de servicios provistos por las infraestructuras fija los nuevos límites de la urbanización.

Pero el efecto del extenso desarrollo de las redes y de la ciudad no es neutro desde un punto de vista social. Por una parte, en Santiago de Chile, como en Los Ángeles, y en la mayoría 
de las metrópolis en el mundo, el crecimiento urbano extensivo conlleva el crecimiento de la segregación y de las desigualdades sociales entre territorios. Por otra parte, cuando las redes delimitan la urbanización, los nuevos límites dibujados no son igualitarios desde el punto de vista social. En la lejana periferia de Santiago, podemos ver que las redes privadas de agua y de electricidad tienden a proveer prioritariamente a los nuevos barrios solventes. En contraste, la construcción de barrios de vivienda social se limita a las zonas ya urbanizadas: los operadores de agua rechazan proveer cualquiera nueva urbanización de carácter social más allá del límite de la zona urbana y frenan la construcción de nuevos barrios modestos.

De esta manera, el éxito del modelo chileno es presentado como un ejemplo de reforma exitosa en un país en desarrollo (Shirley et al., 2000). Su estudio enseńa que el acceso universal fue en realidad logrado a través de importantes inversiones públicas, permitiendo el acceso al servicio a través del acceso a la vivienda, y haciendo solvente a una parte importante de la clientela modesta con subsidios. Las políticas urbanas y sociales ofrecieron las condiciones para el equilibrio y la universalización del mercado urbano de agua potable. Contrariamente a otras ciudades latinoamericanas, como Buenos Aires o La Paz, la privatización del servicio en Chile no buscó incrementar el acceso al servicio; al revés, la universalización de las redes de agua y de saneamiento permitieron al Estado valorizar el capital de su empresa pública. Es así como, en 1999, el 51\% de los activos de EMOS son vendidos al consorcio Aguas de Barcelona-Suez por el importe récord de US\$ 960 millones.

\section{Referencias bibliográficas}

Aguas Andinas (2000). La historia de Aguas Andinas. Santiago de Chile: Aguas Andinas.

Alfaro, R. (1996). Linkages between municipalities and utilities: an experience in overcoming urban poverty. Washington: The World Bank.

Coutard, O. (2002). 'Premium network spaces': a comment. International Journal of Urban and Regional Research, 26, 1, 165-174.

Danière, A. G. \& Gómez-Ibáńez, J. A. (1994). Infrastructure services in Chile: a spatial análisis. Irvine: University of California Irvine, Harvard University.

Ducci, M. E. \& González, M. (2006). Anatomía de la expansión de Santiago 1991-2000. En A. Galetovic (Ed.), Santiago. Dónde estamos y hacia dónde vamos. Santiago de Chile: Centro de Estudios Públicos.

Figueroa, O. (2004). Infraestructura, servicios públicos y expansión urbana en Santiago. En C. De Mattos, M. E. Ducci, A. Rodriguez \& G. Yánez Warner (Eds.), Santiago en la globalización: una nueva ciudad? Santiago: SUR Corporación \& EURE Libros.

Gómez-Lobo, A. \& Contreras, D. (2003). Water subsidy policies: a comparison of the Chilean and Colombian schemes. The World Bank Economic Review, 17, 3, 391-407.

Graham, S. \& Marvin, S. (2001). Splintering urbanism. London: Routledge.

Graham, S. (2002). On technology, infrastructure and the contemporary urban condition: a response to Coutard. International Journal of Urban and Regional Research, 26, 1, 175183.

Icaza, A. M. \& Rodríguez, A. (1988). Estudio de caso, Santiago de Chile. Santiago de Chile: Centro de Investigaciones SUR. 
Larraín, P. (1994). Néolibéralisme et ségrégation socio-spatiale à Santiago du Chili. Cahiers des Amériques Latines, 18.

Ministerio de Planificación, MIDEPLAN (1999). Antecedentes administrativos, operativos y legales del susbsidio al pago del consumo de agua potable y servicio de alcantarillado de aguas servidas. Santiago de Chile: División Social del Ministerio de Planificación y Cooperación.

ODECU (1998). Chile: los consumidores y los servicios públicos domiciliarios. Consumers International.

Oxman, S. \& Oxer, J. P. (2000). Privatización del sector sanitario chileno. Análisis de un proceso inconcluso. Santiago de Chile: Ediciones Cesoc.

Paquette, C. (1998). Grille de présentation de la métropole de Santiago du Chili. Paris: IRD/ PUCA/IUED.

Petermann, A. (2006). ¿Quien extendió a Santiago? Una breve historia del limite urbano, 1953-1994. A. Galetovic (Ed.), Santiago. Dónde estamos y hacia dónde vamos. Santiago de Chile: Centro de Estudios Públicos.

Shirley, M.; Xu, L. C. \& Zuluaga, A. M. (2000) Reforming the urban water system in Santiago, Chile. Washington DC: The World Bank.

Tarr, J. A. \& Dupuy, G. (1988). Technology and the rise of the networked city in Europe and America. Philadelphia: Temple University Press. 